\title{
DISCURSO DEL PRESIDENTE FEDERAL, SR. RICHARD VON WEIZSÄCKER, CON OCASIÓN DEL ACTO OFICIAL CELEBRADO CON MOTIVO DEL "DÍA DE LA UNIDAD ALEMANA" EN LA PHILHARMONIE DE BERLÍN EL 3 DE OCTUBRE DE 1990
}




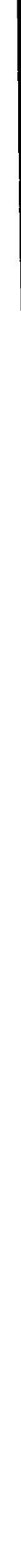


Revista de Derecho Político, núm. 40, 1995, pp. 195-213

\section{DISCURSO DEL PRESIDENTE FEDERAL, SR. RICHARD VON WEIZSÄCKER, CON OCASIÓN DEL ACTO OFICIAL CELEBRADO CON MOTIVO DEL «DÍA DE LA UNIDAD ALEMANA" EN LA PHILHARMONIE DE BERLÍN EL 3 DE OCTUBRE DE 1990}

El Preámbulo de nuestra Constitución, que de aquí en adelante rige para todos los alemanes, proclama cabalmente lo más enjundioso de las emociones que alientan en el día de hoy en nuestros corazones:

Consumamos en libre autodeterminación la unidad y libertad de Alemania. Queremos servir a la paz del mundo en una Europa unida. Afrontamos nuestra misión conscientes de nuestra responsabilidad ante Dios y ante los hombres.

Sentimos de todo corazón inmensa gratitud y júbilo, y a la par nos percatamos de nuestro magno y sagrado deber. La historia de Europa y de Alemania nos brinda ahora una oportunidad sin precedentes. Vivimos una de esas insólitas fases históricas en las que efectivamente las cosas pueden cambiarse a mejor. No olvidemos ni un solo instante lo que esto significa para nosotros.

Tanto fuera como dentro de nuestro país menudean abrumadoras preocupaciones; no dejamos de tenerlo presente. Tomamos en serio las reservas de nuestros vecinos. Asimismo percibimos cuán difícil va a ser responder a las esperanzas depositadas en nosotros desde los cuatro puntos cardinales. Por supuesto que no queremos y no vamos a dejarnos embargar por temores y dudas, sino que vamos a guiarnos por la confianza. Lo decisivo es la firme voluntad de divisar con nitidez nuestros cometidos y proceder a materializarlos de consuno. Esta voluntad nos da fuerzas para armonizar congruentemente las preocupaciones cotidianas con nuestro origen y nuestro futuro en Europa. 
Por primera vez los alemanes no somos un punto litigioso en el orden del día europeo. Nuestra unidad no fue impuesta a nadie, sino pacíficamente acordada. Forma parte de un proceso histórico paneuropeo encaminado a asentar la libertad de los pueblos y establecer un nuevo orden de paz en nuestro continente. Los alemanes nos entregaremos en cuerpo y alma a este objetivo. A él se consagra nuestra unidad.

A partir de ahora tenemos un Estado que nosotros mismos no consideramos ya provisional y cuya identidad e integridad ya no son impugnadas por nuestros vecinos. En el día de hoy la nación alemana unida pasa a ocupar el puesto que se le reconoce en Europa.

El significado de esta aserción lo percibimos a la luz de la relevancia de las fronteras. Ningún país europeo tiene tantos vecinos como nosotros. Durante siglos las fronteras fueron motivo de violentas disputas $y$ espantosos derramamientos de sangre. Hoy en día todos nuestros vecinos $y$ nosotros mismos vivimos dentro de fronteras seguras. No están protegidas únicamente por la renuncia al uso de la fuerza, sino por haberse reconocido cabalmente que su función ha cambiado.

La forzada pérdida del suelo natal fue durísima. Empero, no tiene sentido alguno entablar nuevas disputas fronterizas. Tanto más ardiente es, pues, el afán de quitarles a las fronteras su carácter divisorio. Todas las fronteras de Alemania deben convertirse en puentes hacia nuestros vecinos. Ésa es nuestra voluntad.

Los ideales de la Revolución Francesa sentaron, juntamente con el proceso constitucional de los Estados Unidos y Gran Bretaña, las bases de la democracia occidental. Se formó un concepto de libertad humana asociada al Estado de Derecho que se iría convirtiendo progresivamente en pauta y dechado. No es trasladable a todas partes de buenas a primeras. Ahora bien, siempre que se abre paso - hasta el corazón de Pekínel anhelo de conquistar la libertad política, de potenciar la capacidad de rendimiento y de establecer un Estado social digno para el hombre, los valores y normas de las democracias occidentales constituyen el modelo universal de referencia por el que se guía todo el mundo.

Nosotros los alemanes participamos ya en temprana fecha de la evolución democrática. Sin embargo, en la praxis política no la seguimos con excesivo entusiasmo. El Estado de Derecho había surgido en nuestro 
país a partir de tradiciones propias. En las reformas prusianas de la época napoleónica la autonomía municipal se convirtió en fuente del ideario democrático. La iglesia de San Pablo de Francfort simbolizó para el pueblo el anhelo de unidad, justicia y libertad. Sin duda aspiraba a la unidad, que finalmente se haría realidad en 1871, pero no pudo participar en las decisiones. Una y otra vez hubo esa búsqueda romántica de una tercera vía en la definición del orden interno de Alemania y en la determinación de su engarce en Europa. Pero no fueron más que ilusiones truncadas. Tampoco la República de Weimar fue capaz de modelar una democracia viable.

La fundación de la República Federal de Alemania llevó aparejada en principio la seria preocupación de que desde Occidente se pudiera llegar a afianzar la división de Alemania. No obstante, el camino no fue a parar de nuevo a un callejón sin salida. En un primer momento sólo una parte de los alemanes pudo emprender ese camino. Pero hoy podemos volver a empezar todos juntos.

La unificación de Alemania no es una mera ampliación de la República Federal, es algo distinto. Ha llegado el día en que por primera vez en la historia toda Alemania pasa a ocupar su puesto permanente en el concierto de las democracias occidentales.

Para nosotros mismos y para todos nuestros vecinos ello constituye un acontecimiento de trascendental significación que va a cambiar el centro de Europa. Nosotros vamos a realizar un aporte decisivo al efecto, actuando de consuno con nuestros socios occidentales a partir de la honda compenetración dimanante de nuestros valores y metas comunes.

Durante los últimos cuarenta años el destino quiso que viviéramos divididos en medio de nuestras vecindades europeas, favoreciendo a unos y causando quebranto a otros. Pero fue y sigue siendo nuestro destino alemán común, del cual forman parte la historia y la responsabilidad por sus consecuencias. EI SED trató de decretar una división, creyendo que bastába con proclamar a bombo y platillo la sociedad socialista del futuro para sacudirse el peso de la historia.

Pero en la RDA aquello se vivió y sintió de forma diametralmente distinta. La gente tuvo que soportar a raíz de la guerra unas cargas infinitamente más pesadas que sus compatriotas de la parte occidental. $Y$ 
nunca dejaron de percibir que la rememoración responsable del pasado entraña un imprescindible impulso liberador con vistas al futuro. No bien desaparecieron las machaconas consignas al uso, la gente encaró abiertamente las cuestiones que planteaba la historia.

El mundo ha comprobado con gran respeto cuán sinceramente las fuerzas libres y sobre todo la juventud de la RDA asumieron como un deber reparar las culpas en que había incurrido el antiguo régimen al ignorar su corresponsabilidad por los acontecimientos históricos.

La visita de las presidentas de los dos Parlamentos alemanes libremente elegidos hace escasos meses a Israel para recordar el holocausto causó honda impresión en ese país. Simboliza la comunión de los alemanes precisamente también en su responsabilidad histórica.

La tiranía nacionalsocialista y la guerra que se gestó en su ponzoñoso seno acarrearon a los habitantes de casi toda Europa y de nuestro país gravísimas injusticias y sufrimientos sin cuento. Nunca olvidaremos a las víctimas. $Y$ estamos agradecidos por los crecientes signos de reconciliación entre los hombres y los pueblos.

A lo largo de la posguerra nunca sucumbió la esperanza de que llegaría la hora de la libertad y la superación de la división de Europa, Alemania y sobre todo Berlín. Con todo, nadie podía siquiera imaginar el derrotero que tomarían los acontecimientos. Así pues, el día de hoy lo vivimos como una bienaventuranza. Esta vez la historia nos ha agraciado a los alemanes. Razón de más para hacer cabal examen de conciencia.

Terminada la Segunda Guerra Mundial, la división de Alemania se convirtió en palmaria expresión de la división de Europa. No respondía a la voluntad unánime de los vencedores, sino que, antes bien, fue consecuencia de su disensión. El exacerbado antagonismo Este-Oeste no hizo sino apuntalarla.

Pero no escurramos el bulto. Nadie olvidará que de no haber comenzado Alemania la guerra bajo Hitler nunca se hubiera producido la división.

Bajo el signo de la Guerra Fría y al amparo de la situación de tablas en el plano nuclear se desarrollaria a lo largo de cuarenta años la 
competencia entre los sistemas sociales del Este y del Oeste. Esta fase toca ahora a su fin.

La cúpula soviética, bajo la dirección del presidente Gorbachov, ha reconocido que las reformas encaminadas a la democratización y la implantación de la economía de mercado son ineludibles. Claro que sin libertad tales reformas estarian condenadas al fracaso. A partir de ahí se sacaron valientes conclusiones, renunciando a una tutela sobre los aliados y respetando su libre determinación política. Así se abrieron paso las pacíficas revoluciones de Europa central, oriental y sudoriental, sin parangón en la historia. Así se aceptó que los alemanes se decidieran libremente por la unidad estatal.

El éxito de la línea reformista tal y como viene siendo propugnada por la cúpula soviética se ve aún expuesto a numerosas amenazas. No obstante, ya en estos momentos ha aquilatado su histórico mérito. Y muchos hombres, entre ellos nosotros los alemanes, tienen motivos para estar agradecidos.

No podemos por menos de manifestar nuestro agradecimiento a los movimientos ciudadanos y a los pueblos de Hungría, Polonia y Checoslovaquia. Los habitantes de Varsovia, Budapest y Praga dieron ejemplo. Concibieron la senda hacia la libertad interna en la RDA como parte integrante de un proceso histórico común y como tal lo alentaron.

Imborrable es asimismo el recuerdo de la ayuda que brindaron a los refugiados y por tanto su aporte directo para sortear el muro y las alambradas. En lo sucesivo la Alemania unida aspirará a una relación de vecindad abierta y estrecha con estos países.

La defensa de las libertades y de los derechos humanos es el principal ideal de nuestros aliados $y$ amigos occidentales, sobre todo los americanos, franceses y británicos. Su protección, empeño y cooperación nos han ayudado decisivamente. $Y$, he aquí lo más importante, han depositado su confianza en nosotros. De corazón se lo agradecemos en el día de hoy.

La inequívoca y constructiva actitud de la Comunidad Europea ha atestiguado cuán significativa ha resultado la comprensión de nuestros socios en orden a la unificación de los alemanes.

Es para mí una gran alegría tener hoy aquí entre nosotros al Presidente de la Comisión Europea, Jacques Delors, y a sus colegas y poder testimoniarles nuestro respeto y agradecimiento por su amplitud de miras. 
En el dia de hoy hemos de dar las gracias sobre todo a aquellos alemanes que tuvieron el valor de levantarse en la RDA contra la opresión y la arbitrariedad. Hacía más de diez años que las ideas de la revolución pacífica venían preparándose, profundizándose y difundiéndose en reuniones y plegarias por la paz, en el interior de las iglesias. A pesar de todo, el poder de la policía secreta seguía siendo omnímodo y omnipresente. La amenaza directa de una represión a mano armada no se disiparía hasta bien entrado el otoño de 1989. Hubiera sido del todo comprensible que se hubiera cedido e hincado la rodilla. Pero las esperanzas que alentaban en los corazones de los hombres no podían contenerse por más tiempo.

"Nosotros somos el pueblo", con estas sencillas y grandes palabras se sacudieron los cimientos de todo un sistema, que a la postre acabaría por desplomarse. Estas palabras representaron la voluntad de los hombres de tomar por sí mismos las riendas de la cosa pública, de la res publica. Así fue como la pacífica revolución que tuvo lugar en Alemania adquirió un carácter auténticamente republicano. El hecho de que triunfara al cabo de casi sesenta años de amarga opresión la hace tanto más admirable y verosímil. Los demócratas habían aunado sus esfuerzos con miras a alcanzar la libertad y la solidaridad, misión que a la par nos incumbe a todos.

En el dia de hoy hemos de dar asimismo las gracias a las ciudadanas y ciudadanos de Occidente. Sin la confianza que depositaron en nosotros los pueblos, los alemanes no hubiéramos tenido acceso a la unificación. Esa confianza fue creciendo a lo largo de cuarenta años, a medida que se iba desenvolviendo la República Federal. Los ideales de la democracia liberal y del europeísmo han arraigado en la conciencia de nuestra población.

Los alemanes se han convertido en socios con el corazón en la mano, confiables y respetados. Ello ha propiciado de forma decisiva la adhesión interna de nuestros vecinos y del mundo entero a nuestra unidad.

Esas cuatro palabras se convirtieron en miles. Con titánico esfuerzo se plasmaron acuerdos y tratados merced a los cuales podemos ahora sellar nuestra unidad hacia afuera y hacia adentro. En muchos casos la materia resultaba inextricable. No faltaron los conflictos. La premura de 
tiempo era enorme, una y otra vez. Hubo que trabajar día y noche. Cuando hace falta sabemos arrimar el hombro.

En adelante habrá que aclarar más de un punto oscuro y dirimir más de un litigio. Pero a fin de cuentas la obra que se ha logrado es pasmosa.

Quisiera aprovechar la ocasión para agradecer a los dirigentes políticos de los hasta la fecha dos Estados alemanes, a los órganos legislativos $y$, no en último término, a los tantos $y$ tan ejemplares colaboradores de la administración, la labor realizada. Su entrega a la causa fue ejemplar. Lo conseguido resarce del esfuerzo.

Se ha encontrado la forma de materializar la unidad. Ahora es menester darle contenido e infundirle vida. Los Parlamentos, gobiernos y partidos deben coadyuvar al efecto. Ahora bien, la unidad.sólo puede ser consumada por el pueblo soberano, granar en la mente y el corazón de los hombres. Todo el mundo percibe cuánto falta por hacer. No sería sincero ni provechoso tratar de ocultar las muchas cosas que todavía nos separan.

Las compulsiones externas de la división estaban encaminadas a desunirnos, pero marraron. Siendo como eran inhumanos, el muro y las alambradas no hicieron más que avivar la voluntad de aunarse. Así lo sentimos sobre todo en Berlin, urbe de primordial significación en el pasado $y$ en el futuro.

Viendo y palpando día tras día el muro afirmamos nuestra fe y esperanza en el otro lado. Entre tanto el muro se ha desmoronado y eso es lo decisivo.

Así que ahora que disfrutamos la libertad tenemos que responder cabalmente a su pauta. Hoy distinguimos con mayor claridad que antes las consecuencias de procesos de desarrollo divergentes. El abismo en lo material es lo primero que salta a la vista. Aunque los habitantes de la RDA se vieran confrontados en su vida cotidiana con la economía de la carestía y el apuro, aunque trataran de sacarle el mejor partido posible y trabajaran duro -no lo olvidaremos-, el verdadero alcance de los problemas y por ende la distancia con respecto a la parte occidental no empezarian a evidenciarse hasta hace pocos meses.

Para superar pronto ese desnivel no bastará con que todos se ayuden entre sí, sino que ante todo habrán de guardarse respeto.

Para los alemanes de la antigua RDA la unificación es un proceso de adaptación existencial que les toca directa y personalmente a diario. 
Esto conlleva a menudo exigencias casi sobrehumanas. Una señora me escribió que estaban profundamente agradecidos por la libertad, pero que no se habían imaginado hasta qué punto el cambio les iba a crispar los nervios, exigiendo prácticamente algo así como que se apartaran de sí mismos. Insistía en que de verdad su más profundo anhelo era sacudirse el viejo régimen. Pero el tener que sustituir a la vez casi todos los elementos de la propia vida de la noche a la mañana por algo totalmente nuevo y desconocido sobrepasa con creces la capacidad de asimilación de cualquiera.

Entre los habitantes de la parte occidental de nuestro país la alegría por la caída del muro fue inmensa. Pero muchos no se dan cuenta o incluso rechazan de plano que la unificación tenga algo que ver con sus vidas, que les toque personalmente.

Esto no puede seguir así. Para empezar tenemos que aprender a entendernos mutuamente a un nivel más profundo. Sólo cuando hayamos reconocido plenamente que ambas partes han acumulado valiosas experiencias $y$ aportan importantes cualidades que merece la pena conservar en la unidad iremos por buen camino.

Empecemos por el oeste. Aquí cabe destacar el proceso que al cabo de los años ha llevado a sus habitantes a estimar su república sin caer en afectaciones ni apasionamientos nacionalistas. Es indudable que durante sus cuarenta años de historia la República Federal vivió más de un conflicto profundo entre generaciones, grupos sociales y orientaciones políticas. Con frecuencia se dirimieron con acrimonia, pero sin el prurito destructivo que tan gravemente hipotecó la singladura de la República de Weimar. A pesar de los muchos agravios, la revuelta juvenil de finales de los sesenta contribuyó a profundizar el compromiso democrático de la sociedad.

A partir de la experiencia de que los conflictos podian llegar a zanjarse, fue aglutinándose un acervo común fundado en la confianza en la Constitución. Se disiparon las incertidumbres y vacilaciones. Fue desapareciendo la constante comparación con otros pueblos. No es necesario que todo lo de los demás sea malo para que lo nuestro sea bueno. Y viceversa, no sólo allende las fronteras hay cosas buenas. Se ha ido imponiendo la serenidad en el juicio y en el ánimo.

En la parte occidental hay quienes recién ahora están empezando a descubrir las ventajas de su propio país. Más de uno que en el pasado se contara entre las filas de los más virulentos detractores de la marcha interna de la República Federal ahora se deshace, atenazado por la angustia, en cavilaciones sobre la contingencia de que en la Alemania uni- 
da pudieran llegar a verse afectados el talante liberal, el ideal federalista y la vinculación con Europa. Yo no comparto tales preocupaciones.

Pero sí que es halagüeño que sobre todo los jóvenes se identifiquen con su república en la parte occidental del pais y se den cuenta en este orden de cosas de que la República de Bonn ha conquistado buena fama. A nivel humano se han incorporado e integrado en una comunidad internacional asentada en una cultura consagrada a la libertad, con la cual se identifican plenamente. No quieren perder esa apertura hacia el mundo que han conquistado. ¿Y por qué iba a ser de otro modo?

Pasemos a la RDA. Desde su perspectiva en el momento de la unificación, las carencias y el estado de necesidad de una parte topan con el bienestar de la otra. Claro que sería tan absurdo como inhumano imaginarnos que nos encontramos entre el Este y el Oeste frente a frente como fracasados y triunfadores o incluso como exponentes del bien $y$ del mal.

Son los sistemas los que difieren en sus resultados, no las personas. Esto se pondrá palmariamente de manifiesto cuando los alemanes de la antigua RDA reciban por fin las mismas oportunidades que se vienen disfrutando en la parte occidental desde hace decenios.

Toda vida tiene su sentido y su propia dignidad. Ninguna fase de la vida pasa en balde, y menos cuando se pasa por un trance difícil. A nivel humano los alemanes de la RDA hicieron realidad, bajo condiciones extremadamente adversas, muchas cosas esenciales para el hombre, que esperemos se incorporen a la sustancia de la Alemania unida.

Pasar esto por alto significaría caer una última vez de lleno en la trampa del finiquitado sistema. Su designio consistió en determinar las ideas y propósitos de los hombres mediante la imposición de reglas absolutas tanto en el Estado como en la sociedad, forjando algo así como el nuevo hombre socialista homogéneo. De haber conseguido su propósito ese hombre efectivamente tendría que hincar el pico juntamente con su sistema. Pero el comunismo fracasó en este de todo punto vano intento. Frente a la inverecundia del sistema se impuso la libertad espiritual del hombre: la persona frente a la colectividad.

Los gérmenes de la liberación se desarrollaron bajo la dictadura. Precisamente la falta de libertad política agudiza la vista para distinguir dónde están los límites de una política legítima y que el hombre tiene un ámbito de libertad fuera de los asuntos públicos. La falta de libertad enseña lo que significa ser libre. Vivir en la RDA daba esa experiencia. 
Si bien el Estado atendía a sus ciudadanos con arreglo a su sistema, no es menos cierto que no reconocía al hombre en su necesidad y en su dignidad. Así, a menudo la gente sólo podía sobrevivir si se ayudaba calladamente. La necesidad engendraba comunión. La solidaridad no se quedó en vana abstracción proclamada en grandilocuentes programas básicos, sino que se convirtió en una realidad vivida por los hombres. $\mathrm{Ha}$ cía falta valor y abnegación para trabajar en las parroquias y diaconías. Pero fue una labor venturosa. Dio aplomo. En esas instituciones se atendía por ejemplo a los minusválidos abandonados por el Estado. Así se reverenciaba la vida.

Es cierto que el régimen intentó instrumentalizar con singular porfía el arte y la cultura. Hoy se discute vivamente el comportamiento de los artistas y la calidad de sus obras. No se oculta nada, y eso es bueno. Ahora bien, un rigorismo ético a posteriori sólo resulta convincente y fructífero si está al servicio de la autocrítica. En la RDA el arte en muchos casos no actuó como testimonio político, pero sí como energía para cambiar y profundizar la vida. ¿No lo percibimos ayer y hoy al escuchar la música en los actos festivos?

El régimen engendró un páramo espiritual. A menudo el arte sirvió para sustentar el alma. Hizo su aporte a aquello por lo que nunca dejaron de luchar sobre todo las comunidades de feligreses, a saber, ensanchar el ámbito de la libertad interna. A partir de ahí la gente fue desembarazándose paulatinamente de las patrañas impuestas, el peor de todos los venenos de los decenios pasados, que habían terminado por socavar la confianza en el Estado, en la sociedad, entre vecinos y finalmente también en uno mismo.

El desahogo en la verdad se convirtió así en el más preciado bien, conquistado a pulso por los hombres en su animoso levantamiento.

En la parte occidental no tuvimos que pasar tales pruebas. No podemos por menos de manifestar nuestro respeto y demostrarlo en el proceso de la unificación.

Desde el otoño de 1989 volvió a patentizarse, bajo condiciones externas inconcebibles, el potencial humano de la RDA, tanto en los movimientos ciudadanos como en la mesa redonda y en el renacimiento de la vida municipal.

En la Asamblea Popular hubo quienes tuvieron que asumir de sopetón responsabilidades delicadísimas. Se les llegó a tachar de aficionados. ¿A cuento de qué semejante expresión de censura? Trabajaron con total entrega y por encima de cualesquiera parcialidades para solucionar 
problemas extraordinariamente complejos, sin entregarse al ritual de las confrontaciones partidistas.

Reiteradamente buscaron y hallaron el tan necesario compromiso. En más de una ocasión demostraron cuán valioso es «no esperar o incluso ansiar permanentemente del otro lo peor para que nos cuadre nuestra propia visión de las cosas» (R. SCHRÖDER). No es mal agüero para la democracia el que unos aficionados les pisen así los talones a los políticos profesionales.

Ha llegado la hora de batir el cobre. El reguero de desconfianza que nos dejó la policía secreta es un lastre especialmente grave y abrumador. El sistema se vino abajo, pero pervive el trauma.

Esto tenemos que digerirlo nosotros mismos, en nuestro fuero interno. En esta cuestión no es posible un juicio salomónico externo. Y quienes estuvieron expuestos a la picadura de la víbora son los que mejor pueden colaborar en desarrollar un antídoto:

Lo malo no era la doctrina política del Estado en cuanto tal, sino el hecho de elevarla a verdad absoluta. Creyéndose en posesión de esa verdad absoluta el régimen se arrogó el derecho de imponerla a todo el mundo. La policía secreta fue el instrumento elegido al efecto. Fue así como el designio moral de la cúpula degeneró en abyección. Con medios no por triviales menos desalmados se acechó, espió, chantajeó y corrompió a los ciudadanos, atizando la delación. El método más insidioso era convertir a las víctimas en cómplices.

Sepultar en el olvido la oprobiosa prepotencia de la Stasi sería un baldón de ignominia y una conculcación insufrible de los principios del Estado de Derecho. La justicia sigue su curso. La por lo demás necesaria protección de los datos no debe convertirse en protección de los autores a la hora de examinar los expedientes. Claro que nadie se llamará a engaño sobre el dudoso valor de las pruebas.

En un sistema que no se sostiene sin recurrir a la falsedad también pueden mentir los documentos. Hay una responsabilidad ético-política que no se puede depurar. La culpa va más allá de la punibilidad. Por lo demás, bastante de lo que en un momento posterior apareció co- 
mo culpabilidad resultó ser en verdad algo totalmente distinto, el resultado de un riguroso examen de conciencia bajo una fuerte presión externa.

Las heridas morales tardarán en curar. Llevará su tiempo disipar la desconfianza. Esto es vital. Pero el empeño se malograría si se intentara llevar a cabo una persecución total; no hariamos más que emular a temibles moralistas. La meta es hacer justicia, pero no con miras a la venganza, sino en aras de la reconciliación y la paz interna.

VII

Las inquietudes por el porvenir económico y social son primordiales en este momento. El antiguo sistema fracasó, entre otras razones, por su crisis económica. Es, pues, tanto más importante que los habitantes de la antigua RDA no vivan su libertad recién conquistada como un nuevo estado de necesidad.

Se decidieron por la economía social de mercado acreditada en la parte occidental. La unión monetaria allanó el camino hacia la libertad de circulación y la iniciativa económica. Se impulsaron las premisas jurídicas para el desarrollo de la competencia y la seguridad social.

Ahora bien, un sistema administrativo por sí solo no origina rendimiento económico. Esto es obra de la gente. La economía social de mercado no se materializa en los textos legales, sino a través de las actitudes y el trabajo de la gente, lo cual incluye la experiencia de que la libertad va acompañada de exigencias, de que el auge económico no se produce de la noche a la mañana. Los afectados lo saben mejor que nadie. Para muchos la inflexión es muy profunda y dura: tienen que readaptarse, ponerse al día, cambiar de vivienda, azacanarse, volver a empezar. Pero la experiencia enseña que la propia iniciativa siempre cunde.

No menos decisiva será nuestra cooperación dentro del país unificado. Tenemos que actuar solidariamente, por el bien de todos y cada uno de nosotros. A partir de ya asumimos juntos la responsabilidad por la recuperación económica de los nuevos Estados Federados. Compartimos la aspiración de que esta empresa se vea coronada por el éxito. Porque lo que resulte mal, a la larga será una rémora tanto para los alemanes de la parte occidental como para los de la parte oriental. Nos 
debemos al mandato constitucional de garantizar a todos los alemanes condiciones de vida y oportunidades de desenvolvimiento equivalentes. Esto implica asimismo una actitud abierta y justa frente a nuestros conciudadanos extranjeros.

Con frecuencia se oye por estas fechas que no se trata de quitar nada a nadie, sino de cómo van a repartirse los frutos del crecimiento. Es una hermosa fórmula, muy propia del lenguaje del marketing empleado en la comunicación política de los tiempos que corren. Sin embargo, visto objetivamente podría no significar otra cosa que un aplazamiento de la distribución a un tiempo futuro. $Y$ eso puede resultar demasiado tarde para la suerte de mucha gente.

Según un refrán chino, las montañas se convierten en oro cuando los hermanos trabajan juntos. No tiene por qué ser oro, y además sin hermanas tampoco cuaja. Sea como fuere, hay que tener presente que unirse significa aprender a compartir. La unidad alemana no se podrá financiar únicamente mediante empréstitos de alta rentabilidad. Hay que virar, tanto a nivel público como privado, para ayudar, ahorrar, dar. La viabilidad de esta empresa se patentiza en numerosos ejemplos admirables, por ejemplo en los hospitales, escuelas y universidades, en empresas y agrupaciones, en asociaciones y familias. También los hermanamientos entre ciudades pueden convertirse en sólidas piedras angulares de nuestra convivencia.

Ninguna teoría, por muy lúcida que sea, ningún cálculo, por muy pulido que sea, es susceptible de sustituir la capital experiencia de los hombres de todas las culturas y de todas las religiones de que el ser humano sólo se da auténticamente a su prójimo cuando comparte con él. Sólo estaremos auténticamente unidos cuando estemos dispuestos a dedicarnos a los demás. Podemos hacerlo, y muchos, creo que la mayoría, así lo quieren.

\section{VIII}

El Estado nacional no está acabado. Empero, quien crea que el futuro sólo se puede forjar a través de él vive en un tiempo pretérito. Hoy en día ninguna nación puede desempeñar por sí sola sus funciones más importantes. Los sistemas modernos no piensan ni funcionan en clave nacional. Esto es aplicable tanto a la seguridad como a la ecología, a la economía y a la energía, al transporte y a las telecomunicaciones. En 
nuestra época soberanía significa participación en el seno de la comunidad internacional.

En este orden de cosas la Comunidad Europea creó un modelo convincente. Aglutinó a nivel supranacional competencias del Estado nacional de singular relevancia a efectos de una vecindad pacífica. En la pugna entre los sistemas del Este y del Oeste la Comunidad proporcionó impulsos determinantes en orden a las reformas en el Este.

La Guerra Fría está superada. La libertad y la democracia se han abierto paso pronto en todos los países. En adelante ya pueden - sin compulsiones de poderes prepotentes, sino motu proprio- estrechar y apuntalar institucionalmente sus relaciones de forma que por primera vez emerja un orden de convivencia y paz comunitario. Comienza así un capítulo completamente nuevo en la historia de los pueblos de Europa. Su meta es la integración paneuropea.

Es una meta de extraordinario alcance. Podemos arribar a buen puerto, pero también zozobrar. No debemos perder el tiempo. La opción que se nos presenta es clara: o forjamos la unión de Europa o recaemos, siguiendo penosos ejemplos históricos, en los antagonismos nacionalistas.

Ahora mismo es imperioso ofrecer perspectivas tangibles para el desarrollo económico y social de los países de Europa central, oriental y sudoriental. La libertad recién conquistada tiene que hallar terreno propicio para arraigar. Por eso no debe echarse a perder en la necesidad. La Comunidad Europea puede prestar una ayuda decisiva en este terreno. La evolución de toda Europa va a depender fundamentalmente de ella.

A los alemanes nos corresponde un papel clave. Propugnamos que Occidente siga una política constructiva y conjunta respecto a los paises del Este. Ahora que todos los alemanes han vuelto a ser vecinos directos de los polacos, ese pueblo tan importante para nosotros, hemos de insistir en que la Comunidad concierte con Polonia un acuerdo de asociación, pero no más adelante sino en un plazo lo más breve posible. Lo mismo vale para Checoslovaquia y Hungría.

La Unión Soviética, por citar otro ejemplo de trascendental significación, necesita una estrecha cooperación europea a su proyecto, sembrado de dificultades. Quiere superar la distancia que la venía separando de Europa. Ha reconocido que la unificación de Alemania no constituye obstáculo en esa línea, sino que, antes bien, es una premisa a tal fin. Éste es el mensaje más importante de la en verdad trascen- 
dental Conferencia "Dos más Cuatro". $Y$ todos sabemos que la futura estabilidad de Europa depende del capital aporte de Moscú. La frontera occidental de la Unión Soviética no debe convertirse en la frontera oriental de Europa.

Los alemanes enviamos tales señales a toda Europa desde nuestra firme trabazón con Occidente, trabazón que ha marcado nuestra vida en la República Federal, movilizado nuestras energías y despertado nuevos bríos. Por nada del mundo vamos a arriesgar nuestra cohesión atlántica y europea. Es nuestro interés por excelencia, compartido por nuestros compatriotas de los nuevos Estados Federados. Saben cuán importante va a seguir siendo sobre todo la amistad con Francia y por su parte se alegran de esa nueva vecindad directa.

Sólo haremos progresos si actuamos de consuno con nuestros socios occidentales, sobre todo en el seno de la Comunidad y a través de la misma. Todo lo que los países miembros hacen por toda Europa a través de la Comunidad los fortalece a ellos y a la Comunidad.

Para nosotros los alemanes la mejor manera de defender nuestros intereses y llegar a desterrar las preocupaciones de nuestros vecinos será volcarnos como el que más en la consolidación de la Comunidad y avanzar sin dilación, tal y como prometimos, en la senda hacia la unión económica y monetaria y la unión política.

La pauta de la Alemania unida reza, pues, plena integración en Occidente y apertura hacia toda Europa. Habremos cumplido nuestra misión si al cabo del tiempo se puede afirmar que el capítulo decisivo hacia la unión de Europa en su conjunto comenzó con la superación de la división de Alemania.

Cuanto más rápidamente solucionemos los europeos nuestros propios conflictos mejor podremos cumplir nuestros compromisos globales. Bajo el signo de la Guerra Fría los europeos exportaron una y otra vez tensiones y armas al hemisferio sur. Ahora se trata de impulsar el proceso CSCE, reducir el nivel de armamentos y reforzar las ayudas al sur.

La imponente frase bíblica que habla de convertir las espadas en arados, a la cual se apeló en las jornadas de la revolución pacífica, no significa en el momento presente que haya que renunciar a una capacidad de defensa razonable y suficiente; significa que hay que erradicar el hambre del mundo y poner coto a la miseria. El testimonio de tantos y tantos jóvenes de todas las partes de la Alemania unida nos alienta en este empeño. 


\section{IX}

Entre las responsabilidades que compartimos con los demás pueblos destaca especialmente la que asumimos frente al medio ambiente. El hombre no debe cargar sobre la Naturaleza todo lo que llega a tener o hacer gracias a la técnica o la economía. No está en juego únicamente la habitabilidad del planeta, la salvaguardia del medio natural. El hombre puede destruir la Creación, que no es obra suya y de la que no le es dable disponer. Sin embargo, se ha arrogado ilegítimamente esa facultad. La viabilidad ética y a la postre también biológica del hombre dependerá de su sentido de la responsabilidad en el ejercicio de su libertad.

La tarea que tenemos ante nosotros es a todas luces global. Incumbe a todos los Estados del mundo, a todas las administraciones, a todos los municipios $y$ a todos los ciudadanos. Siendo una tarea general lleva implícita a la par una cuestión política que se nos plantea a todos. En el contexto concreto de la nueva andadura de nuestra nación ello exige una clara respuesta normativa.

La Ley Fundamental rige ya para todos los alemanes. En el Tratado de Unificación convinimos en examinar el tema de las normas relativas a los fines del Estado. Se trata de mandatos constitucionales que no deben coartarse mediante leyes restrictivas, sino que han de vincular tanto al legislador como a todos nosotros.

¿No es la protección de la Naturaleza, hoy por hoy carente de amparo legal en cuanto tal, el objetivo que más urgentemente debe incorporarse al catálogo de los fines supremos de nuestra sociedad? ¿Tenemos acaso una misión más alta que preservar la Creación y proteger por ende a la posteridad? Que yo sepa, no.

\section{$x$}

Queridos compatriotas, en el día de hoy constituimos nuestro nuevo Estado común. Hasta qué punto cuaje la empresa de la unidad a nivel humano es algo que no depende en absoluto de un tratado entre gobiernos, de una Constitución o de cualesquiera decisiones del legislador. Antes bien, dependerá de la conducta de cada uno de nosotros, de nuestro propio talante abierto y de nuestra entrega a los demás. Éste es el uple- 
biscito cotidiano" (RENAN) del que emanará la índole de nuestra comunidad.

Abrigo el convencimiento de que sabremos sortear los viejos y nuevos escollos. Podemos conjugar en una pujante totalidad el patriotismo constitucional profesado por los unos con la solidaridad humana vivida por los otros. Compartimos la voluntad de cumplir los magnos cometidos que esperan de nosotros nuestros vecinos.

No desconocemos que otros pueblos del mundo atraviesan en el momento presente situaciones harto más difíciles. La historia nos brinda la oportunidad. Vamos a aprovecharla con esperanza y confianza. Y la alegría, así lo escuchamos anoche, la alegría que sentimos, es un estro divino. 